\title{
Minds on the blink: The relationship between inattentional blindness and attentional blink
}

\author{
Vanessa Beanland • Kristen Pammer
}

Published online: 16 November 2011

(C) Psychonomic Society, Inc. 2011

\begin{abstract}
Failures of conscious visual awareness occur when specific task demands prevent an observer from detecting a stimulus that would otherwise be clearly visible. Two examples are inattentional blindness (IB) and attentional blink (AB). IB is the failure to detect an unexpected stimulus when attention is otherwise engaged. $A B$ describes the inability to detect a second target that is presented within $180-500 \mathrm{~ms}$ of the first target. Previous research has suggested that similar cognitive processes underlie both IB and $\mathrm{AB}$; however, they are distinct phenomena, and no evidence has directly linked the two. We tested the same group of observers on an IB task and an $\mathrm{AB}$ task. Consistent with our hypotheses, we found that "nonnoticers" who failed to detect an unexpected stimulus in the IB task also demonstrated a larger $\mathrm{AB}$ effect. This suggests that some observers may be more generally susceptible to failures of conscious visual awareness, regardless of specific context.
\end{abstract}

Keywords Visual attention · Consciousness · Inattentional blindness $\cdot$ Attentional blink

Specific task demands often induce "blindness" and prevent observers from detecting clearly visible stimuli. Two wellknown variants of induced blindness are inattentional

\footnotetext{
V. Beanland $\cdot \mathrm{K}$. Pammer

Department of Psychology, The Australian National University, Canberra, ACT, Australia

V. Beanland $(\triangle)$

Accident Research Centre, Monash Injury Research Institute,

Monash University,

Clayton, VIC, Australia

e-mail: vanessa.beanland@monash.edu
}

blindness (Mack \& Rock, 1998) and attentional blink (Raymond, Shapiro, \& Arnell, 1992). They are often conceptually associated (e.g., Chun \& Marois, 2002) because both involve failure to detect a stimulus due to attentional processing limitations, and empirical studies have implicated similar processes in both phenomena. For example, an individual's working memory capacity predicts both their likelihood of experiencing inattentional blindness (Hannon \& Richards, 2010; Richards, Hannon, \& Derakshan, 2010; Seegmiller, Watson, \& Strayer, 2011) and the magnitude of their attentional blink (e.g., Colzato, Spapé, Pannebakker, \& Hommel, 2007). Evidence demonstrates that some individuals are less susceptible to attentional blink (Martens, Munneke, Smid, \& Johnson, 2006) but no studies have correlated attentional blink and inattentional blindness within the same sample. The aim of the present study was to examine attentional blink performance in relation to inattentional blindness and thereby determine whether some people are more or less susceptible to failures of awareness generally.

Inattentional blindness (Mack \& Rock, 1998) is the failure to consciously detect an unexpected stimulus when one's attention is occupied by another task. Inattentional blindness is a robust effect that can occur for a variety of stimuli, from briefly presented static images (Mack \& Rock, 1998) to highly salient moving objects (Most et al., 2001) and even people (Simons \& Chabris, 1999). Although there are no formal theories explaining the mechanisms of inattentional blindness, it is considered a consequence of selective attention (Neisser, 1979); observers tend not to experience inattentional blindness unless their attention is simultaneously engaged by another, primary task. Attentional set (Folk, Remington, \& Johnston, 1992) plays a significant role in determining 
whether unexpected objects will be noticed: Observers are more likely to notice unexpected items that are categorically or featurally similar to attended targets and are less likely to notice items that are similar to unattended distractors (Koivisto \& Revonsuo, 2007; Most, Scholl, Clifford, \& Simons, 2005; Most et al., 2001). Primary task demands also predict inattentional blindness, with higher rates of inattentional blindness arising during tasks of greater difficulty (Cartwright-Finch \& Lavie, 2007; Simons \& Chabris, 1999; Simons \& Jensen, 2009) and tasks that require more working memory (Fougnie \& Marois, 2007) or more visual short-term memory (Todd, Fougnie, \& Marois, 2005).

Relatively little is known about why under identical circumstances one person will experience inattentional blindness but another will not. Although inattentional blindness is a robust effect, it is almost impossible to replicate using identical stimuli (Simons, 2010), making it difficult to obtain a reliable measure of how frequently individuals experience inattentional blindness. Several studies have examined individual differences in inattentional blindness by correlating the incidence of inattentional blindness with performance on other tasks. To date, only working memory has revealed a significant effect, with individuals who experience inattentional blindness demonstrating less working memory capacity (Hannon \& Richards, 2010; Richards et al., 2010; Seegmiller et al, 2011). Remarkably, inattentional blindness is not related to the amount of visual information that a person can monitor or maintain: It is not predicted by an individual's visual working memory capacity (Hannon \& Richards, 2010), functional field of view, or their multiple-object tracking ability (Memmert, Simons, \& Grimme, 2009). Practicing the primary task reduces inattentional blindness (Neisser, 1979; Richards et al., 2010), but it is the absolute difficulty of the primary task, rather than the individual's proficiency at the task, which predicts the likelihood of inattentional blindness (Simons \& Jensen, 2009). In sum, current evidence suggests that primary task demands significantly predict inattentional blindness but, surprisingly, the observer's ability to perform the primary task does not predict inattentional blindness.

Attentional blink (Raymond et al., 1992) refers to an inability to detect a second target (T2) when it is presented within $180-500 \mathrm{~ms}$ of the first target (T1). Most attentional blink experiments use rapid serial visual presentation (RSVP) and present both targets in the same spatial location embedded within a sequence of distractor items. Targets and distractors are typically categorically different (e.g., letters vs. digits or red vs. green items). T2 detection is usually the worst at lag 2 or lag 3 (i.e., two or three items after T1), and in most cases returns to ceiling by lag 8 . T2 identification at lag 1 is often equal or superior to $\mathrm{T} 1$ identification, a phenomenon known as lag 1 sparing (Potter, Chun, Banks, \& Muckenhoupt, 1998). Like inattentional blindness, the attentional blink occurs because attentional processes are engaged by another taskprocessing $\mathrm{T} 1$ - and observers do not experience attentional blink if they are instructed to report only $\mathrm{T} 2$ and ignore $\mathrm{T} 1$ (Raymond et al., 1992). Attentional blink is a robust and reliable effect, which can be repeatedly induced using identical stimuli, although intensive training on other tasks can marginally reduce blink magnitude (i.e., improve detection of $\mathrm{T} 2$ at short lags). For example, one study suggested that meditation training can significantly reduce attention blink magnitude (Slagter et al., 2007), and several have suggested that training individuals to play action video games reduces blink magnitude (see Green \& Bavelier, 2006, for a review), although other research has failed to replicate the video game finding (Boot, Blakely, \& Simons, 2011).

Several studies have investigated individual differences in attentional blink. Observers who are better able to inhibit distractors show an attenuated attentional blink effect overall, but greater interference if $\mathrm{T} 2$ also appears as a priming distractor following T1 (Dux \& Marois, 2008). This suggests that "nonblinkers" are better able to inhibit task-irrelevant items (distractors), which helps them focus on only the task-relevant items (T1 and T2). Working memory is also related to attentional blink: People with lower operation span demonstrate a deeper attentional blink (Colzato et al., 2007), and increasing working memory load increases attentional blink magnitude, as evidenced by poorer T2 detection at lag 3 but not at lag 8 (Akyürek, Hommel, \& Jolicœur, 2007). Attentional blink is not affected by simple maintenance of information in shortterm memory; however, adding a short-term memory task decreases overall RSVP performance but does not affect blink magnitude, since the decrement in performance is constant across all lags (Akyürek \& Hommel, 2006). Similarly, nonverbal intelligence predicts overall RSVP performance but not attentional blink specifically (Colzato et al., 2007). This is relevant because attentional blink magnitude is not correlated with general RSVP performance (e.g., T1 accuracy, single-target accuracy, mean T2 accuracy across all lags) when T1 accuracy is controlled for by assessing only $\mathrm{T} 2$ performance on trials in which $\mathrm{T} 1$ is correctly reported (Arnell, Howe, Joanisse, \& Klein, 2006). Attentional blink is also not related to performance on reaction time (RT) tasks (Arnell et al., 2006).

Many studies have also compared attentional blink performance between groups, finding a larger blink for groups including older adults (Lahar, Isaak, \& McArthur, 2001), people with ADHD (Hollingsworth, McAuliffe, \& Knowlton, 2001), and those high in impulsivity (Li, Chen, Lin, \& Yang, 2005). The only specific population to 
consistently report a reduced attentional blink magnitude is action video game players (Green \& Bavelier, 2003), although in some studies the reduction is not statistically significant (Boot, Kramer, Simons, Fabiani, \& Gratton, 2008) and, as was mentioned previously, there is dispute over whether gaming is causally related with reduced blink magnitude. Even in the general population, attentional blink magnitude varies considerably, with some observers recording lag 2 deficits of up to $80 \%$ as compared with lag 8 performance, whereas others record no measurable blink at all (i.e., nearperfect identification of both $\mathrm{T} 1$ and $\mathrm{T} 2$ across all lags). People in the latter category, nonblinkers, typically demonstrate faster processing of stimuli (Martens et al., 2006).

In contrast with inattentional blindness, there are several specific theories that attempt to explain the attentional blink, although none fully account for the multitude of empirical findings (see Dux \& Marois, 2009, for a review). One of the best-supported and most widely accepted explanations of attentional blink is Chun and Potter's (1995) two-stage model. In the first stage of processing, stimuli are rapidly detected and some features are analyzed, which provides a basis for selecting targets. Almost all stimuli (including distractors) are submitted for processing at Stage 1, but stimulus representations are brief and highly susceptible to over-writing, particularly in an RSVP situation in which another stimulus is presented within $100 \mathrm{~ms}$. Task-relevant items are selected on the basis of initial Stage 1 processing, but to reach conscious awareness, stimuli must proceed to a second capacity-limited processing stage. Whereas Stage 1 processing is rapid, Stage 2 processing is more time intensive, and its duration is typically longer than the stimulus onset asynchrony between T1 and T2 at early lags in an attentional blink paradigm. An exception to this is that if T2 immediately follows $\mathrm{T} 1$ and uses the same target identification criteria (e.g., both are letters), both targets will enter Stage 2 simultaneously, and lag 1 sparing will occur (Chun \& Potter, 1995). Once T1 processing is complete, which can take up to $500 \mathrm{~ms}$, T2 is able to enter Stage 2, which explains "recovery" from the attentional blink observed at later lags.

Although inattentional blindness and attentional blink have never been directly correlated, evidence suggests that they involve similar mechanisms. As was discussed, inattentional blindness and attentional blink are both predicted by the working memory load of tasks and working memory capacity of individuals. In both paradigms, stimuli are more likely to reach conscious awareness if they have emotional salience or personal relevance, such as one's own name (Mack \& Rock, 1998; Shapiro, Caldwell, \& Sorensen, 1997), highly emotive words (Anderson \& Phelps, 2001; Mack \& Rock, 1998), photographs of faces (Devue, Laloyaux, Feyers, Theeuwes, \& Brédart, 2009; Landau \& Bentin, 2008) or even stylized "smiley" faces (Mack, Pappas, Silverman, \& Gay, 2002; Mack \& Rock, 1998). This suggests that undetected stimuli undergo semantic processing in both inattentional blindness and attentional blink, which is further supported by evidence that unreported targets in attentional blink paradigms evoke event-related potentials associated with semantic processing (Luck, Vogel, \& Shapiro, 1996). Finally, concurrent distractions such as listening to music can reduce both inattentional blindness and attentional blink (Beanland, Allen, \& Pammer, 2011; Olivers \& Nieuwenhuis, 2005). On the basis of this evidence, it seems likely that attentional blink and inattentional blindness involve related cognitive processes; therefore, it is probable that people who experience inattentional blindness will exhibit a "deeper" blink.

In the present study, we tested the same group of observers on both an inattentional blindness and an attentional blink task. It was predicted that participants who failed to notice the unexpected stimulus during the inattentional blindness task ("non-noticers") would also exhibit a larger attentional blink, with poorer performance at early lags (i.e., lags 2-4) but equivalent lag 1 and lag 8 performance.

\section{Method}

\section{Participants}

Sixty observers ( 23 female, 37 male; $M_{\text {age }}=23.3$ years, $S D=$ 2.9) with normal or corrected-to-normal visual acuity provided informed consent and received financial compensation. Of these, 24 observers (one female, 23 male) were video game players who played first person shooter (action) video games at least $4 \mathrm{hr}$ per week. We deliberately recruited gamers in order to increase the variance of attentional blink magnitude within the sample, since previous research has indicated that habitual gamers are more likely to be nonblinkers (Green \& Bavelier, 2003).

\section{Apparatus}

Stimuli were presented on computer using a $21-\mathrm{in} .85-\mathrm{Hz}$ CRT monitor and custom software programs written in Presentation (Neurobehavioural Systems, Inc). Viewing distance was approximately $60 \mathrm{~cm}$ for most participants, yielding a display area of $35.9^{\circ} \times 27.3^{\circ}$ visual angle. Participants responded using a button box comprising eight buttons labeled 2-9.

Stimuli and procedure

Inattentional blindness The inattentional blindness task comprised six 45-s trials. Trials 1-4 contained four white 
targets $\left(90 \mathrm{~cd} / \mathrm{m}^{2}\right.$; Weber contrast 0.58$)$ and four black distractors $\left(6 \mathrm{~cd} / \mathrm{m}^{2}\right.$; Weber contrast -0.89$)$ moving along independent paths on a light gray background $\left(57 \mathrm{~cd} / \mathrm{m}^{2}\right)$. Targets and distractors were shaped like ghosts and Pacman characters $\left(2.0^{\circ} \times 2.0^{\circ}\right)$. Observers were asked to press "9" on the button box whenever a white target bounced within the display. Trials 5 (critical trial) and 6 (full attention trial) also contained a dark gray "+" sign $\left(2.0^{\circ} \times 2.0^{\circ} ; 24 \mathrm{~cd} / \mathrm{m}^{2}\right.$; Weber contrast -0.58 ) that traveled right-left along the horizontal midline during the period $30-45 \mathrm{~s}$ (see Fig. 1). Following the critical trial, participants were questioned to ascertain whether they had noticed the unexpected stimulus. Observers were coded as "noticers" if they reported detecting the unexpected stimulus and correctly described its shape. Prior to the full attention trial, participants were instructed to watch the display without tracking any objects or making any responses. Observers who failed to detect the unexpected stimulus on this trial were excluded from analysis.

Attentional blink Each trial consisted of 18 distractors and two targets, which were presented using RSVP in Times New Roman 30-point font (see Fig. 2). Each item was presented for $94 \mathrm{~ms}$ with no interstimulus interval (presentation rate 10.6 items $/ \mathrm{s}$ ). Distractors were all uppercase letters except those that might be confused with numbers (I, O, Q, S). The targets were digits 2-9 inclusive. T2 appeared either immediately after T1 (lag 1) or after one, two, three, or seven distractors (lags 2, 3, 4, 8). Participants entered their responses via the button box. There were 100 experimental trials (20 for each lag) preceded by five practice trials.

Data analysis All analyses were evaluated using an alpha level of .05. Huynh-Feldt degrees of freedom corrections were applied where Mauchly's test indicated violations of sphericity. For inattentional blindness task accuracy, weighted error scores were calculated using the formula: (Actual - Reported bounces)/Actual bounces * 100. Trial 1 was considered a practice trial and excluded from analysis. Attentional blink accuracy reversals (i.e., trials in which observers identified both targets but ordered them incorrectly) were coded as correct.

\section{Results}

Inattentional blindness (IB) Data from six observers were excluded from analysis due to: failing to detect the unexpected stimulus under full attention (one) and realizing the experimental topic (five). Overall, 26\% of observers noticed the unexpected stimulus (74\% IB). Primary task accuracy was analyzed using a 2 (IB: noticers, non-noticers) $\times$ 4 (Trial: 2, 3, 4, 5) mixed factorial ANOVA on weighted error scores and did not vary between noticers and non-noticers, $F$ $(1,52)=2.29, p=.136, \eta_{\mathrm{p}}^{2}=.04$. Accuracy varied significantly across trials due to practice effects, $F(3,156)=$ $8.19, p<.001, \eta_{\mathrm{p}}^{2}=.14$. Error on Trial $4(M=17.2, S E=$ 1.6) was significantly lower than on Trial $2, M_{\text {diff }}=-4.4$, $S E=1.0, p<.001, \mathrm{CI}_{95}[-7.2,-1.7]$, and Trial 3, $M_{\text {diff }}=$ 3.4, $S E=0.9, p=.002, \mathrm{CI}_{95}[-5.8,-1.0]$, but not on Trial $5, M_{\text {diff }}=-1.6, S E=1.0, p=.641, \mathrm{CI}_{95}[-4.4,1.1]$.

Attentional blink ( $A B)$ Two means were calculated for each lag: T1 accuracy and T2 accuracy on trials in which $\mathrm{T} 1$ was correctly identified (T2|T1). Repeated measures ANOVA revealed a significant main effect of lag on T2|T1 accuracy, $F(2.2,118.0)=38.22, p<.001, \eta_{\mathrm{p}}^{2}=.42$. There was significant lag 1 sparing, with mean lag 1 accuracy $(M=$ $93.1 \%, S E=1.1 \%)$ being significantly higher than lag 2 $(M=69.4 \%, S E=2.9 \%)$, lag $3(M=68.3 \%, S E=3.7 \%)$, and lag $4(M=74.7 \%, S E=3.0 \%), p<.001$, for all comparisons. There was also significant lag 8 recovery, with accuracy $(M=88.0 \%, S E=1.7 \%)$ being significantly higher than lags 2, 3, and 4, $p<.001$, for all comparisons. Lag 8 was significantly worse than lag $1, M_{\text {diff }}=-5.1 \%$, $S E=1.7 \%, p=.036, \mathrm{CI}_{95}[-10.0,-0.2]$, and lag 4 was significantly better than lag $3, M_{\text {diff }}=6.4 \%, S E=1.8 \%$, $p=.010, \mathrm{CI}_{95}[1.0,11.8]$. There was no difference between lags 2 and $3(p=1.000)$, or lags 2 and $4(p=.131)$.

To examine individual differences, we obtained each person's maximum blink and blink magnitude. The maximum blink was their lowest accuracy score out of lags 2, 3, and 4. For most observers (54\%), this was at lag 2; 35\% experienced their maximum blink at lag 3 , and $11 \%$ at lag 4. Maximum blink scores ranged from $6 \%$ to $100 \%$ $(M=62 \%, S D=26 \%)$. Blink magnitude was calculated by graphing each person's results and obtaining a measure for the slope between lags 2 and lag $8,{ }^{1}$ which ranged from -1.3 (no blink, slight decline at lag 8) to 10.7 (large blink), $M=3.4, S D=3.3$.

$I B-A B$ relationship Stepwise discriminant analysis was used to assess which aspects of $\mathrm{AB}$ performance best predicted IB classification (i.e., noticer or non-noticer) with five predictors entered: blink magnitude, maximum blink, lag of maximum blink, mean T1 accuracy across all lags, and mean $\mathrm{T} 2 \mid \mathrm{T} 1$ accuracy across all lags. Variables were

\footnotetext{
${ }^{1}$ Previous researchers have commonly used difference scores (e.g., lag 7 - lag 2; lag 8 - maximum blink) as a measure of blink magnitude (e.g., Arnell et al., 2006; Colzato et al., 2007; Dux \& Marois, 2008). Calculating the slope of each observer's attentional blink magnitude is a more sensitive measure of blink magnitude than difference scores because it factors in all measured lags between lag 2 and lag 8 .
} 
Fig. 1 Single frames from the inattentional blindness task. Observers were required to respond via button press whenever the white targets bounced within the display. a. During the first four trials, only the white targets and black distractors appeared. b. During the critical trial (Trial 5) and the full attention trial (Trial 6), a gray “+” appeared after $35 \mathrm{~s}$ and crossed the display horizontally right-left, exiting after $40 \mathrm{~s}$

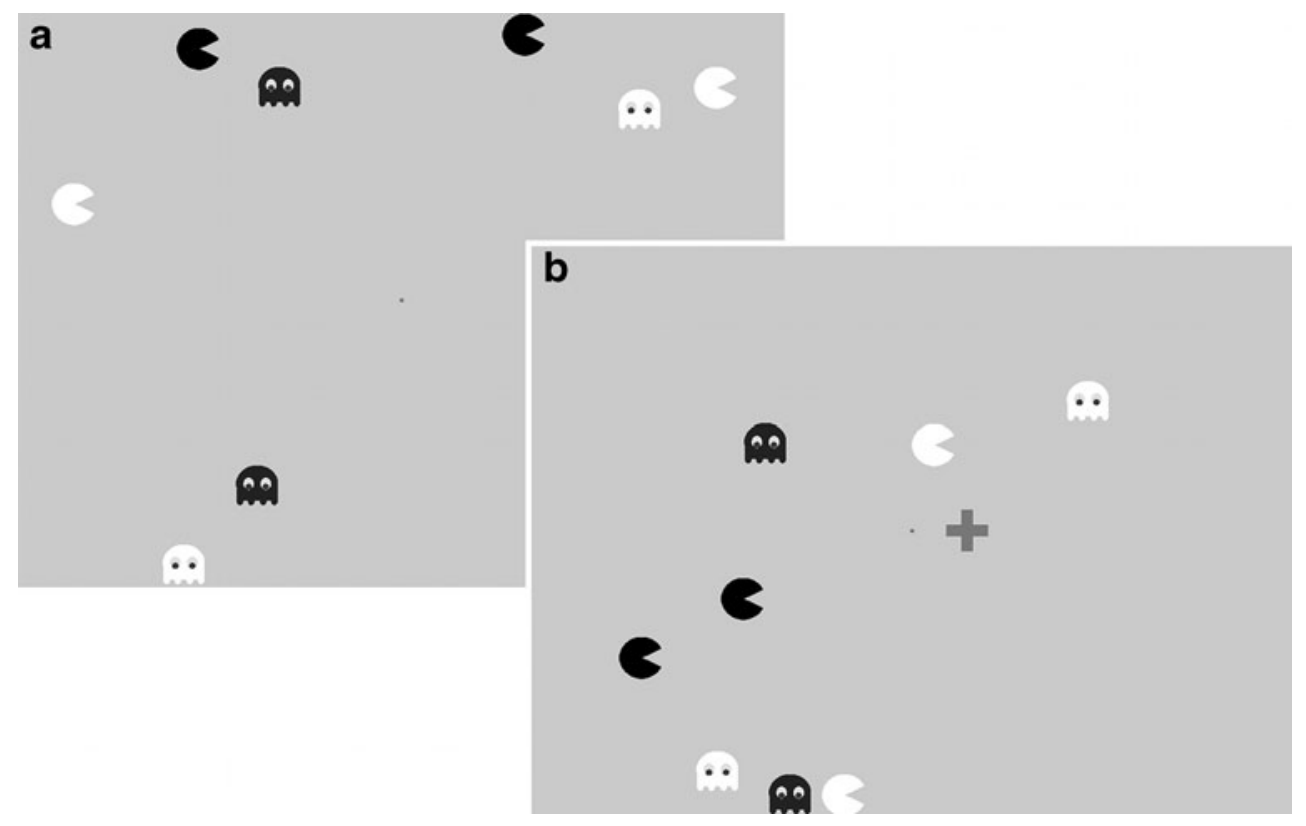

entered based on Wilks' lambda values. Blink magnitude was entered at Step $1, F(1,52)=4.43, p=.040$, with lag of maximum blink added at Step 2, $F(2,51)=4.69, p=$ .013. Mean T1 accuracy, mean T2|T1 accuracy, and size of maximum blink did not independently predict IB and thus were not entered in the model. All three factors were significantly correlated with blink magnitude (mean T1 accuracy, $r=-374, p=.005$; mean T2|T1 accuracy, $r=-.677, p<.001$; maximum blink, $r=-.811, p<.001)$.

The final discriminant model with two predictors (blink magnitude, lag of maximum blink) significantly predicted
IB classification, Wilks' Lambda $=.845, \chi^{2}(2)=8.62$, $p=.013$, and accounted for $15.5 \%$ of the variance between noticers and non-noticers (Canonical $R^{2}=.394$ ). The cross-validated model correctly categorized $78 \%$ of participants (95\% of non-noticers, $29 \%$ of noticers). Nonnoticers had a deeper blink and experienced maximum blink at lag 2, whereas noticers had a shallower blink with a dip at lag 3 (see Fig. 3).

Given our deliberate recruitment of gamers in this experiment, we also ran separate analyses for gamers and non-gamers to ensure that the $\mathrm{IB}-\mathrm{AB}$ relationship was not
Fig. 2 Representative trial from the attentional blink task. Each trial began with a fixation point, which was immediately followed by a sequence of 20 items. There were zero, one, two, three, or seven distractors between the first target (T1) and the second target (T2), meaning that it appeared at lags 1, 2, 3, 4 and 8 . There were at least two distractors presented before $\mathrm{T} 1$ and at least five distractors presented after $\mathrm{T} 2$, meaning the targets were subject to both forward and backward masking

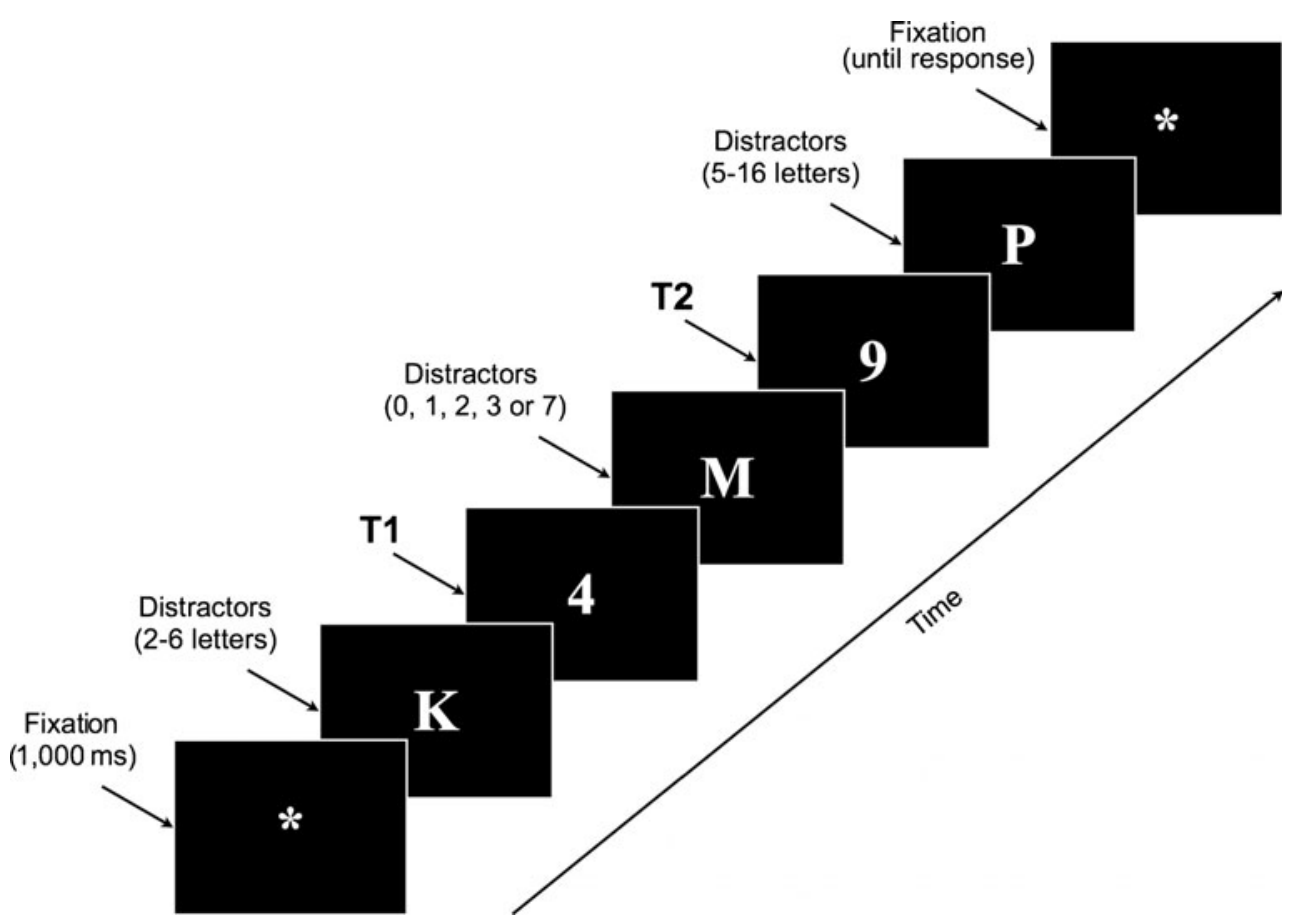




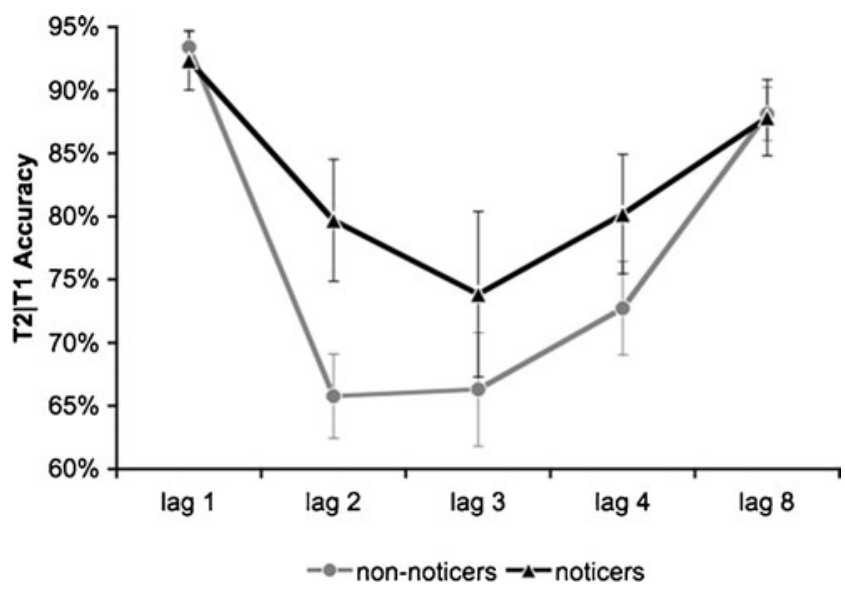

Fig. 3 Results for the attentional blink task, comparing noticers versus non-noticers of the unexpected stimulus from the inattentional blindness task. Non-noticers showed a larger blink magnitude, as exhibited by poorer performance at lags 2, 3 and 4. Error bars represent standard errors

due solely to the unique visuospatial abilities of gamers. The same pattern emerged for both groups (i.e., nonnoticers had a deeper blink); however, in the separate analyses, the effect reached significance only for the gamer group. It appears that this is due to a reduction in statistical power and to the fact that there were few "nonblinkers" in the non-gamer group, whereas there were several in the gamer group.

\section{Discussion}

As was predicted, observers who failed to detect the unexpected stimulus in our inattentional blindness task also displayed a greater attentional blink magnitude. This finding supports the idea that inattentional blindness and attentional blink share some underlying cognitive processes. Performance at lag 1 and lag 8 was identical for noticers and non-noticers, which indicates a genuine difference in attentional blink magnitude rather than poorer overall RSVP performance by non-noticers. This is important, because some studies have claimed that certain groups (e.g., dyslexic readers) exhibit a deeper or prolonged attentional blink when they in fact display consistently poorer performance across all lags, leaving no difference in attentional blink after controlling for differences in baseline task performance (see Badcock, Hogben, \& Fletcher, 2008). Overall, our findings suggest that some people may be more susceptible to failures of conscious awareness in general. This raises the possibility that observers who are highly susceptible to inattentional blindness may also be more prone to other failures of awareness, such as change blindness, which arguably has more commonalities with inattentional blindness than atten- tional blink does (see Jensen, Yao, Street, \& Simons, 2011, for a review of change blindness and inattentional blindness). Although both inattentional blindness and attentional blink are failures of conscious awareness, there is an important distinction between the two paradigms: Attentional blink involves the failure to detect a known task-relevant item when items are presented sequentially, whereas inattentional blindness involves the failure to detect an unexpected and task-irrelevant item when items are presented simultaneously. Given this distinction, it is unsurprising that the overlap between the two tasks is relatively small, with attentional blink accounting for just under $16 \%$ of the variance in inattentional blindness.

An additional reason for the imperfect overlap between inattentional blindness and attentional blink relates to potential measurement error within the inattentional blindness task. In addition to fluctuations due to varying task demands and stimulus characteristics, inattentional blindness varies within individuals in a way that is hard to measure systematically, since traditional repeated measures designs cannot be used. This means that observers who were non-noticers in this experiment could be noticers in another situation, or vice-versa. Only two published studies have retested participants on inattentional blindness tasks using stimuli highly similar to those that they had already seen. In one study, whether observers noticed an unexpected stimulus in Experiment 1 did not predict whether they would notice the unexpected stimulus in Experiment 2 (Beanland \& Pammer, 2010). In another study, observers were more likely to notice an item that they had previously seen as an unexpected stimulus (a person in a gorilla suit) but were less likely to detect other unexpected events (Simons, 2010). Thus, although correlating a single occurrence of inattentional blindness with performance on other cognitive tasks, such as the attentional blink, may be the best available means of investigating individual differences in inattentional blindness, the results are not unequivocal.

\section{Theoretical implications for inattentional blindness}

Given the current dearth of theoretical frameworks explaining inattentional blindness and the limitations regarding repeated measures designs, the present study provides an important contribution to the literature. In particular, it suggests that inattentional blindness and attentional blink share common underlying mechanisms, which means that some aspects of attentional blink theories might be applicable to inattentional blindness, such as Chun and Potter's (1995) two-stage model. As was previously discussed, there is evidence of semantic processing for unexpected stimuli in inattentional blindness paradigms, and for unreported T2s and even irrelevant distractors in 
attentional blink paradigms (Maki, Frigen, \& Paulson, 1997). The implication is that these undetected stimuli receive Stage 1 processing without proceeding to Stage 2, although the reasons for failing to proceed likely differ for inattentional blindness versus attentional blink. In attentional blink, because the observer is explicitly attempting to detect $\mathrm{T} 2$, the target should receive Stage 2 processing whenever capacity limits permit ${ }^{2}$ (i.e., whenever T2 appears either at lag 1, or after $\mathrm{T} 1$ has completed Stage 2 processing). In contrast, because inattentional blindness involves an apparently irrelevant stimulus, whether the unexpected stimulus reaches Stage 2 will be determined by multiple factors. Processing capacity, which is determined by the combination of task demands and an individual's own abilities (e.g., working memory), is still important, but inattentional blindness rates vary significantly, even when task demands are held constant, and these variations are often due to stimulus characteristics (Most et al., 2001, 2005). If an object is similar to attended targets, it may be mistaken for a target and thus is more likely to reach Stage 2 processing, whereas if it is similar to a distractor, it will be suppressed as irrelevant.

Throughout the present article, we have framed the discussion primarily in terms of non-noticers, arguing that some observers are more susceptible to failures of conscious awareness. However, there is an alternative interpretation for our findings, which is that some people are less susceptible to failures of awareness. As was mentioned, we deliberately recruited habitual video game players in order to increase our likelihood of obtaining a subset of nonblinkers. Consequently, we also increased the primary task demands for our inattentional blindness task in order to avoid ceiling performance by gamers, which in turn increased the rate of inattentional blindness (Simons \& Jensen, 2009). ${ }^{3}$ Therefore, given the high rate of inattentional blindness, it seems possible that those observers who detected the unexpected stimulus were people who are less susceptible to failures of conscious awareness generally: They were the same people who are nonblinkers in attentional blink experiments. Even if this is the case, we

\footnotetext{
${ }^{2}$ This is not to say that capacity limits are the only determinant of attentional blink. As Dux and Marois (2009) noted, attentional blink likely results from multiple factors, including attention, memory, and processing speed - and to some extent these determine processing capacity for a given situation. Our point here is that because the inattentional blindness stimulus is purportedly irrelevant, there are additional factors that determine whether it reaches conscious awareness.

${ }^{3}$ Although several studies have suggested that gamers have superior visuospatial abilities to non-gamers, there is currently no evidence that gamers differ from nongamers in susceptibility to inattentional blindness. The only published study that has investigated inattentional blindness in gamers found no difference between gamers and nongamers (Murphy \& Spencer, 2009) and forthcoming work from our lab found similar results.
}

believe the existence of such a group remains a valuable research finding.

\section{Subtypes of inattentional blindness}

When considering the relationship between attentional blink and inattentional blindness, it is worth noting that there are distinct subtypes of inattentional blindness, and not all subtypes are likely to demonstrate the same relationship with attentional blink. Different paradigms can elicit slightly different phenomena, because "inattentional blindness" is essentially an umbrella term for failures of visual awareness that result from lack of attention. In the present experiment, we used a sustained inattentional blindness paradigm with dynamic stimuli. Other paradigms have used static stimuli and presented the entire task display, including the unexpected stimulus, for around 125-200 ms (Mack \& Rock, 1998; White \& Aimola Davies, 2008). Static inattentional blindness paradigms demand focused attention in order to complete the primary task, but not necessarily selective attention, since the observer can presume that the entire briefly presented display will be task relevant. In contrast, selective attention and attentional set largely determine the likelihood of inattentional blindness in a dynamic task, because observers are typically required to selectively ignore distractors. Sustained inattentional blindness can occur even when there are no to-be-ignored distractors in the display (Koivisto \& Revonsuo, 2008), but the rate of inattentional blindness is significantly higher when distractors are present $(22 \%$ vs. $52 \%)$. The number of task-irrelevant items has no effect - one distractor or five distractors will yield similar rates of inattentional blindness - the crucial factor is that observers have something to ignore (Koivisto \& Revonsuo, 2008).

Most (2010) raised the possibility that there are at least two subtypes of inattentional blindness, which he described as spatial inattentional blindness and central inattentional blindness. Spatial inattentional blindness is due to the allocation of overt or covert visual attention away from the unexpected stimulus. This type of inattentional blindness is fairly straightforward; it occurs simply because observers are attending to a different part of the display. In contrast, Most argued that central inattentional blindness arises from processing bottlenecks or capacity limitations. Observers cannot detect the unexpected stimulus because they have insufficient cognitive resources to process it properly, either because of task demands or because of their own level of cognitive capacity (e.g., working memory or perceptual processing speed). Central inattentional blindness may be further subdivided according to the specific cognitive processes that prompt it under different circumstances (e.g., top-down attentional settings vs. engaging in highly demanding tasks). 
The existence of different subtypes of inattentional blindness has implications for generalizing results across studies, particularly those examining individual differences. For example, working memory appears to influence central inattentional blindness but does not necessarily predict spatial inattentional blindness (Most, 2010). Because a distinct theoretical framework underlies why each subtype of inattentional blindness occurs, different kinds of people may be more or less likely to experience different subtypes of inattentional blindness. Situational predictors may also vary between subtypes, although in many instances, it is likely that situational predictors will determine the subtype of inattentional blindness that occurs. For example, one set of task demands may induce spatial inattentional blindness, but another set of task demands may induce central inattentional blindness. Although Most (2010) raised a valid and important point about the distinction between these two subtypes, it is likely that they are not discreet categories, and many instances of inattentional blindness will involve both "spatial" and "central" processes. In the present experiment, we used a paradigm that assessed central inattentional blindness, and the results suggest, as Most hypothesised, that this subtype is related to attentional blink.

\section{Conclusion}

The present study provides the first direct evidence of a relationship between inattentional blindness and attentional blink. Previously, the two phenomena were discussed in conjunction with each other simply because both represent the "dark side of attention" or occasions where observers fail to detect clearly visible stimuli (Chun \& Marois, 2002). Our results suggest that, despite the conceptual distinctions between inattentional blindness and attentional blink, the failure to detect irrelevant stimuli and the failure to detect relevant stimuli share common cognitive processes. This finding has important theoretical relevance, since the first empirical demonstration that failures of conscious awareness arise from underlying mechanisms, despite the fact that they are induced by very different task demands.

Author Note We thank Olivia Metcalf for assistance with data collection, Andy Thomson for programming assistance, and Steve Most and Mark Nieuwenstein for their helpful comments on this manuscript.

\section{References}

Akyürek, E. G., \& Hommel, B. (2006). Memory operations in rapid serial visual presentation. European Journal of Cognitive Psychology, 18, 520-536. doi:10.1080/09541440500423160
Akyürek, E. G., Hommel, B., \& Jolicœur, P. (2007). Direct evidence for a role of working memory in the attentional blink. Memory and Cognition, 35, 621-627.

Anderson, A. K., \& Phelps, E. A. (2001). Lesions of the human amygdala impair enhanced perception of emotionally salient events. Nature, 411, 305-309. doi:10.1038/35077083

Arnell, K. M., Howe, A. E., Joanisse, M. F., \& Klein, R. M. (2006). Relationships between attentional blink magnitude, RSVP target accuracy, and performance on other cognitive tasks. Memory and Cognition, 34, 1472-1483.

Badcock, N. A., Hogben, J. H., \& Fletcher, J. F. (2008). No differential attentional blink in dyslexia after controlling for baseline sensitivity. Vision Research, 48, 1497-1502. doi:10.1016/j.visres.2008.03.008

Beanland, V., Allen, R. A., \& Pammer, K. (2011). Attending to music decreases inattentional blindness. Consciousness and Cognition., 20, 1282-1292. doi:10.1016/j.concog.2011.04.009

Beanland, V., \& Pammer, K. (2010). Gorilla watching: Effects of exposure and expectations on inattentional blindness. In W. Christensen, E. Schier, and J. Sutton (Eds.), ASCS09: Proceedings of the 9th Conference of the Australasian Society for Cognitive Science (pp. 12-20). Sydney, Australia: Macquarie Centre for Cognitive Science. doi:10.5096/ASCS20093

Boot, W. R., Blakely, D. P., \& Simons, D. J. (2011). Do action video games improve perception and cognition? Frontiers in Psychology, 2, 226. doi:10.3389/fpsyg.2011.00226

Boot, W. R., Kramer, A. F., Simons, D. J., Fabiani, M., \& Gratton, G. (2008). The effects of video game playing on attention, memory, and executive control. Acta Psychologica, 129, 387-398. doi:10.1016/j.actpsy.2008.09.005

Cartwright-Finch, U., \& Lavie, N. (2007). The role of perceptual load in inattentional blindness. Cognition, 102, 321-340. doi:10.1016/ j.cognition.2006.01.002

Chun, M. M., \& Potter, M. C. (1995). A two-stage model for multiple target detection in rapid serial visual presentation. Journal of Experimental Psychology: Human Perception and Performance, 21, 109-127. doi:10.1037/0096-1523.21.1.109

Chun, M., \& Marois, R. (2002). The dark side of visual attention. Current Opinion in Neurobiology, 12, 184-189. doi:10.1016/ S0959-4388(02)00309-4

Colzato, L. S., Spapé, M. M. A., Pannebakker, M. M., \& Hommel, B. (2007). Working memory and the attentional blink: Blink size is predicted by individual differences in operation span. Psychonomic Bulletin \& Review, 14, 1051-1057.

Devue, C., Laloyaux, C., Feyers, D., Theeuwes, J., \& Brédart, S. (2009). Do pictures of faces, and which ones, capture attention in the inattentional-blindness paradigm? Perception, 38, 552-568. doi: $10.1068 / \mathrm{p} 6049$

Dux, P. E., \& Marois, R. (2008). Distractor inhibition predicts individual differences in the attentional blink. PLOS ONE, 3, e3330. doi:10.1371/journal.pone.0003330

Dux, P. E., \& Marois, R. (2009). The attentional blink: A review of data and theory. Attention, Perception, \& Psychophysics, 71, 1683-1700. doi:10.3758/APP.71.8.1683

Folk, C. L., Remington, R. W., \& Johnston, J. C. (1992). Involuntary covert orienting is contingent on attentional control settings. Journal of Experimental Psychology: Human Perception and Performance, 18, 1030-1044. doi:10.1037/0096-1523.18.4.1030

Fougnie, D., \& Marois, R. (2007). Executive working memory load induces inattentional blindness. Psychonomic Bulletin \& Review, 14, 142-147.

Green, C. S., \& Bavelier, D. (2003). Action video game modifies visual selective attention. Nature, 423, 534-537. doi:10.1038/ nature 01647

Green, C. S., \& Bavelier, D. (2006). The cognitive neuroscience of video games. In P. Messaris \& L. Humphreys (Eds.), Digital 
media: Transformations in human communication. New York, NY: Peter Lang.

Hannon, E. M., \& Richards, A. (2010). Is inattentional blindness related to individual differences in visual working memory capacity or executive control functioning? Perception, 29, 309319. doi:10.1068/p6379

Hollingsworth, D. E., McAuliffe, S. P., \& Knowlton, B. J. (2001). Temporal allocation of visual attention in adult attention deficity hyperactivity disorder. Journal of Cognitive Neuroscience, 13, 298-305. doi:10.1162/08989290151137359

Jensen, M. S., Yao, R., Street, W. N., \& Simons, D. J. (2011). Change blindness and inattentional blindness. Wiley Interdisciplinary Reviews: Cognitive Science, 2(5), 529-546. doi:10.1002/wcs.130

Koivisto, M., \& Revonsuo, A. (2007). How meaning shapes seeing. Psychological Science, 18, 845-849. doi:10.1111/ j.1467-9280.2007.01989.x

Koivisto, M., \& Revonsuo, A. (2008). The role of unattended distractors in sustained inattentional blindness. Psychological Research, 72, 39-48. doi:10.1007/s00426-006-0072-4

Lahar, C. J., Isaak, M. I., \& McArthur, A. D. (2001). Age differences in the magnitude of the attentional blink. Aging, Neuropsychology, and Cognition, 8, 149-159. doi:10.1076/anec.8.2.149.842

Landau, A. N., \& Bentin, S. (2008). Attentional and perceptual factors affecting the attentional blink for faces and objects. Journal of Experimental Psychology: Human Perception and Performance, 34, 818-830. doi:10.1037/0096-1523.34.4.818

Li, C. R., Chen, S.-H., Lin, W., \& Yang, Y.-Y. (2005). Attentional blink in adolescents with varying levels of impulsivity. Journal of Psychiatric Research, 39, 197-205. doi:10.1016/j. jpsychires.2004.06.003

Luck, S. J., Vogel, E. K., \& Shapiro, K. L. (1996). Word meanings can be accessed but not reported during the attentional blink. Nature, 383, 616-618. doi:10.1038/383616a0

Mack, A., \& Rock, I. (1998). Inattentional blindness. Cambridge, MA: MIT Press.

Mack, A., Pappas, Z., Silverman, M., \& Gay, R. (2002). What we see: Inattention and the capture of attention by meaning. Consciousness and Cognition, 11, 488-506. doi:10.1016/S1053-8100(02) 00028-4

Maki, W. S., Frigen, K., \& Paulson, K. (1997). Associative priming by targets and distractors during rapid serial visual presentation: Does word meaning survive the attentional blink? Journal of Experimental Psychology: Human Perception and Performance, 23, 1014-1034.

Martens, S., Munneke, J., Smid, H., \& Johnson, A. (2006). Quick minds don't blink: Electrophysiological correlates of individual differences in attentional selection. Journal of Cognitive Neuroscience, 18, 1423-1438. doi:10.1162/jocn.2006.18.9.1423

Memmert, D., Simons, D. J., \& Grimme, T. (2009). The relationship between visual attention and expertise in sports. Psychology of Sport and Exercise, 10, 146-151. doi:10.1016/j. psychsport.2008.06.002

Most, S. B. (2010). What's "inattentional" about inattentional blindness? Consciousness and Cognition, 19, 1102-1104. doi:10.1016/j.concog.2010.01.011

Most, S. B., Scholl, B. J., Clifford, E. R., \& Simons, D. J. (2005). What you see is what you set: Sustained inattentional blindness and the capture of awareness. Psychological Review, 112, 217 242. doi:10.1037/0033-295X.112.1.217
Most, S. B., Simons, D. J., Scholl, B. J., Jimenez, R., Clifford, E., \& Chabris, C. F. (2001). How not to be seen: The contribution of similarity and selective ignoring to sustained inattentional blindness. Psychological Science, 12, 9-17. doi:10.1111/1467-9280.00303

Murphy, K., \& Spencer, A. (2009). Playing video games does not make for better visual attentional skills. Journal of Articles in Support of the Null Hypothesis, 6, 1-20.

Neisser, U. (1979). The control of information pickup in selective looking. In A. D. Pick (Ed.), Perception and its Development: A Tribute to Eleanor J. Gibson (pp. 201-219). Hillsdale, NJ: Erlbaum.

Olivers, C. N. L., \& Nieuwenhuis, S. (2005). The beneficial effect of concurrent task-irrelevant mental activitiy on temporal attention. Psychological Science, 16, 265-269. doi:10.1111/ j.0956-7976.2005.01526.x

Potter, M. C., Chun, M. M., Banks, B. S., \& Muckenhoupt, M. (1998). Two attentional deficits in serial target search: The visual attentional blink and an amodal task-switch deficit. Journal of Experimental Psychology: Learning, Memory, and Cognition, 24, 979-992. doi:10.1037/0278-7393.24.4.979

Raymond, J. E., Shapiro, K. L., \& Arnell, K. M. (1992). Temporary suppression of visual processing in an RSVP task: An attentional blink? Journal of Experimental Psychology: Human Perception and Performance, 18, 849-860. doi:10.1037/0096-1523.18.3.849

Richards, A., Hannon, E. M., \& Derakshan, N. (2010). Predicting and manipulating the incidence of inattentional blindness. Psychological Research, 74, 513-523. doi:10.1007/s00426-009-0273-8

Seegmiller, J. K., Watson, J. M., \& Strayer, D. L. (2011). Individual differences in susceptibility to inattentional blindness. Journal of Experimental Psychology: Learning, Memory, and Cognition, 37, 785-791. doi:10.1037/a0022474

Shapiro, K. L., Caldwell, J., \& Sorensen, R. E. (1997). Personal names and the attentional blink: A visual "cocktail party" effect. Journal of Experimental Psychology: Human Perception and Performance, 23, 504-514. doi:10.1037/0096-1523.23.2.504

Simons, D. J. (2010). Monkeying around with the gorillas in our midst: Familiarity with an inattentional-blindness task does not improve the detection of unexpected events. i-Perception, 1, 3-6. doi: $10.1068 / 10386$

Simons, D. J., \& Chabris, C. F. (1999). Gorillas in our midst: Sustained inattentional blindness for dynamic events. Perception, 28, 1059-1074. doi:10.1068/p2952

Simons, D. J., \& Jensen, M. S. (2009). The effects of individual differences and task difficulty on inattentional blindness. Psychonomic Bulletin \& Review, 16, 398-403. doi:10.3758/ PBR.16.2.398

Slagter, H. A., Lutz, A., Greischar, L. L., Francis, A. D., Nieuwenhuis, S., Davis, J. M., \& Davidson, R. J. (2007). Mental training affects distribution of limited brain resources. PLoS Biology, 5, e138. doi:10.1371/journal.pbio.0050138

Todd, J., Fougnie, D., \& Marois, R. (2005). Visual short-term memory load suppresses temporo-parietal junction activity and induces inattentional blindness. Psychological Science, 16, 965-972. doi:10.1111/j.1467-9280.2005.01645.x

White, R. C., \& Aimola Davies, A. (2008). Attention set for number: Expectation and perceptual load in inattentional blindness. Journal of Experimental Psychology: Human Perception and Performance, 34, 1092-1107. doi:10.1037/0096-1523.34.5.1092 